eISSN: 2172-9077

https://doi.org/10.14201/fjc20191879

\title{
DOCUMENTAL EN FEMENINO
}

\section{Documentary films: women's perspectives}

\author{
Dr. Pablo CALVO DE CASTRO \\ Profesor de Tiempo Completo \\ Universidad de Medellín, Colombia \\ E-mail: pcalvo@udem.edu.co \\ (iD) http://orcid.org/0000-0002-7537-2349
}

El presente monográfico pone su interés en el análisis del rol que desempeñan las mujeres en el cine documental a los dos lados de la cámara. La manera en la que problemáticas específicamente femeninas son representadas mediante este formato audiovisual, es analizada tomando como referencia tanto cuestiones específicas como generales o transversales. Pero es el análisis del rol de la mujer como realizadora el que está más intensamente desarrollado aquí. Desde estudios transversales de la cinematografía documental árabe y latinoamericana -con especial incidencia en México- producida por mujeres, hasta el acercamiento a cuestiones que modelan la vanguardia creativa y experimental con orientación de género, los investigadores y las investigadoras que han acudido a la llamada de este monográfico ofrecen estudios de gran interés respecto a un binomio que aúna las reivindicaciones en pro de la igualdad de derechos con una herramienta que se ha demostrado de gran importancia para el cambio social. El documental, además, está viviendo en estas primeras décadas del siglo XXI una eclosión en tanto la irrupción de los medios digitales ha permitido una verdadera democratización del género. Pero este incremento de las posibilidades de producción está también visibilizando la trascendencia de las aportaciones de las mujeres realizadoras - postergadas históricamente por una mirada antropocéntrica- en un momento en el que las derivaciones de las temáticas y las técnicas de registro de la realidad son más ricas que nunca.

Como apuntamos, México tiene gran protagonismo en este monográfico, quizá por estar su sociedad inmersa en un proceso de violencia generada por los problemas con el narcotráfico y la corrupción más recientes, pero también con cuestiones de mayor recorrido histórico, por ejemplo: la identidad indígena, los problemas de acceso a las tierras en las comunidades campesinas, la falta de tolerancia y de cohesión social, entre otros, que se pueden sintetizar en unos altos niveles de desigualdad, sufrida especialmente por las mujeres.

La cineasta y académica Mari Carmen de Lara Rangel, una de las principales exponentes del cine documental en México desde los años 80 y directora de la Escuela Nacional de Artes y Cinematografía de la UNAM nos ofrece, en su artículo titulado El cine documental mexicano becho por mujeres, un mapa de situación privilegiado en el que analizar los principales retos a los que se han tenido que enfrentar las mujeres 
cineastas. Esta doble vertiente, que por un lado ofrece un valioso testimonio desde el rol de la creación y por otro analiza, a nivel teórico, el contexto de desarrollo de su cine, contribuye a explicar cómo en la actualidad, a través de los movimientos feministas y los medios digitales, las voces de las realizadoras pueden ser escuchadas e influir a nivel global.

Pero las mencionadas problemáticas que asolan México también han generado, por desgracia, un contexto de violencia estructural que, dentro de la cronificación del machismo que permea en todos los ámbitos de la sociedad, encuentra un nicho para expandirse. En este sentido, el cine documental cobra gran importancia como herramienta de denuncia en una sociedad totalmente desprotegida ante los ataques procedentes, incluso, de quienes están responsabilizados y legitimados por el ejercicio democrático para proteger a la ciudadanía. El artículo de Javier Juárez, con título El cine documental hecho por mujeres como instrumento de denuncia y visibilización de los feminicidios sexuales y las desapariciones de mujeres en Ciudad Juárez, realiza un ejercicio de revisión del papel del cine documental en este contexto desde una doble vertiente. En primer lugar, incorpora una muestra de películas realizadas específicamente por mujeres documentalistas, introduciendo un importante factor de visibilización de estas cineastas, en tanto aportan una resignificación a las líneas de trabajo que vienen desarrollando autores comprometidos con lo social, en los últimos años, rompiendo con la mirada antropocentrista dominante. Por otra parte, se analiza la representación que se ha realizado en el cine documental de los feminicidios sexuales y los asesinatos de mujeres en Ciudad Juárez (México) a través de dos ejemplos que muestran una problemática social de primer orden sobre la que, a día de cierre de este monográfico, no han aparecido visos de solución, mucho menos de reparación a las víctimas.

Ampliando el foco en cuanto a la adscripción geográfica, pero también realizando una exploración prospectiva, Carolina Bracco nos ofrece con Panorama de mujeres documentalistas árabes, un recorrido por un fenómeno cinematográfico relativamente reciente ya que los primeros títulos del conjunto de cinematografías seleccionadas por la autora aparecen ya en la década de los setenta. Además, el cine documental hecho por mujeres en países árabes es un ámbito muy poco estudiado y tradicionalmente han sido escasas las oportunidades para aquellas cineastas que quieren visibilizar problemáticas que les afectan dentro de sociedades profundamente desiguales si las analizamos desde una perspectiva de género.

También con la intención de realizar un análisis transversal se incorpora en este monográfico el artículo Mujeres tras las cámaras en el documental latinoamericano. Conclusiones de un estudio transversal de la evolución bistórica, a fin de ofrecer un recorrido por las aportaciones al cine documental en América Latina. En este contexto, una vez más, la desigualdad estructural está presente de manera constante en cada ámbito social. A partir de una muestra que incorpora un periodo histórico de casi cien años y las principales cinematografías de la región, tratamos de dilucidar en qué medida las aportaciones de las documentalistas han sido históricamente invisibilizadas y cómo en la actualidad sus aportaciones determinan el momento de eclosión y de verdadera democratización del género, una vez hacen su aparición los medios digitales con el cambio de siglo. Si bien este es un proceso que afecta al documental a nivel global, la especial idiosincrasia de América Latina ha influido en gran medida en la escasez de oportunidades en el desarrollo de proyectos documentales en tanto el acceso a los recursos se convierte en muchas ocasiones en un reto insalvable. 
En un plano mucho más concreto, analizando una de las principales vías del documental contemporáneo -la reflexiva-, se encuentra Ana Borisova, que en su artículo Dicotomias documentadas: las obras de Ksennia Khrabrykh como la ventana hacia la otredad realiza un profundo estudio de la manera en la que la realizadora rusa Ksennia Khrabrykh aborda, a través de los planteamientos desarrollados y reflexionados en sus películas, cuestiones del yo y del otro, de lo masculino y lo femenino. Lo hace desde el escrutinio del discurso conceptual, el formato narrativo y la manera en la que esta singular cineasta evoca el objeto de estudio desde las teorías feministas.

Dentro de las ramificaciones más recientes que está viviendo el formato documental, Purificación Subires, en su artículo El webdoc como herramienta en la lucha por la igualdad: En la brecha (2018) de Lab RTVE, analiza las principales características del webdoc como evolución interactiva y multimedial del documental cinematográfico y televisivo. Esto lo hace a partir del análisis de En la brecha (2018), un título producido por el ente público RTVE con motivo de la celebración del Día Internacional por la Igualdad Salarial en 2018.

Por último, se analiza el documental autobiográfico desde la concepción femenina. Este formato audiovisual se convierte hoy en una de las corrientes más importantes del género documental. Una de sus principales impulsoras es la cineasta belga Chantal Akerman. Los investigadores Mar Marcos Molano y Pablo Moreno Ruíz, en su artículo "News from home" de Chantal Akerman: el documental autobiográfico en el contexto del documental contemporáneo, llevan a cabo un análisis de la relación materno filial de la directora que, a partir de lo íntimo y lo emocional, reflexiona sobre la relación entre las mujeres y el pulso generacional entre madres e hijas. Esto deriva en un análisis del yo, en una película -del año 1977- que se convierte en seminal de las múltiples reflexiones e indagaciones que los cineastas contemporáneos están realizando de lo autorreferencial y lo autobiográfico en las últimas décadas.

Con todo esto, el recorrido por el cine documental en femenino introduce una cierta dosis de activismo, en tanto es necesaria una visibilización de las aportaciones de las mujeres cineastas en el cine documental, así como de su representación en el mismo, practicando activamente la reflexión constante en este apasionante formato audiovisual y la lucha por la igualdad de derechos. 
